\title{
Follicular steroidogenesis and oocyte maturation after superovulation of goats (Capra hircus) with gonadotrophins
}

\author{
J. Kumar*, J. C. Osborn, A. W. N. Cameron and A. O. Trounson \\ Centre for Early Human Development, Monash University, Monash Medical Centre, 246 Clayton \\ Road, Clayton, Victoria 3168, Australia
}

\begin{abstract}
Summary. Follicles were sampled at three different times after treatment with $1200 \mathrm{iu}$ pregnant mares' serum gonadotrophin (PMSG) or $12 \mathrm{mg}$ ovine follicle-stimulating hormone (FSH), and from untreated control animals. The meiotic status and protein synthesis of the oocyte from each follicle was determined and correlated with the intrafollicular concentration of oestradiol and progesterone. Significantly higher amounts of oestradiol were present in PMSG-treated animals at sponge withdrawal than in FSH-treated and control goats. Twenty hours later, both oestradiol and progesterone concentrations in the PMSG group were higher than those in the FSH group, and were equivalent to control animals at the onset of oestrus. At $18 \mathrm{~h}$ after the administration of human chorionic gonadotrophin (hCG), oestradiol decreased markedly in all three treatment groups, whereas progesterone remained significantly higher in PMSGtreated follicles. Although these high concentrations of intrafollicular steroids were associated with a higher incidence of premature condensation of chromatin in oocytes, the two events were not causally related. Moreover, cytoplasmic maturation was not prematurely activated in these oocytes and a changed pattern of protein synthesis was observed in oocytes from all three treatment groups after the hCG injection. Whereas disturbances in follicular steroidogenesis of oestradiol and progesterone occur in vivo in goats superovulated with PMSG, they do not underlie the premature activation of the initial stages of nuclear maturation in oocytes but are associated with normal cytoplasmic maturation.
\end{abstract}

Keywords: follicles; oocytes; maturation; steroidogenesis; superovulation; gonadotrophins; goat

\section{Introduction}

Superovulation of goats with pregnant mares' serum gonadotrophin (PMSG) induces premature condensation of chromatin without germinal vesicle breakdown in a significantly higher proportion of oocytes than does ovine follicle-stimulating hormone (FSH) (Kumar et al., 1990). This apparent abnormality in the timing of nuclear maturation occurs within $48 \mathrm{~h}$ of gonadotrophin treatment and is not observed in unstimulated animals. In sheep and cattle, premature activation of oocyte maturation has also been demonstrated after treatment with superovulatory doses of PMSG (Moor et al., 1985; Callesen et al., 1986). In both of these species, the untimely induction of nuclear and cytoplasmic maturation was associated with disturbances in the concentration of steroids in follicular fluid. In addition, altering the follicular environment by the use of inhibitors of steroidogenesis during oocyte maturation in vitro induced anomalies in the nuclear and cytoplasmic

\footnotetext{
*Present address: Department of Obstetrics and Gynaecology, National University Hospital, National University of Singapore, Lower Kent Ridge Road, Singapore-0511.
} 
maturation of sheep oocytes which manifested as gross abnormalities at fertilization (Moor et al., 1980; Osborn \& Moor, 1983a; Osborn et al., 1986).

It is possible, therefore, that in goats, as in cattle and sheep, abnormalities in follicular steroidogenesis underlie the premature condensation of chromatin observed in oocytes after superovulation with PMSG (Kumar et al., 1990), and that these alterations in follicular steroids are also associated with premature activation of cytoplasmic maturation. The present study examined this hypothesis by comparing the nuclear and cytoplasmic maturational status of oocytes and the steroid content of fluid in follicles taken from goats superovulated with PMSG with those from unstimulated and FSH-treated animals.

\section{Materials and Methods}

The experiments were conducted in conjunction with our earlier study (Kumar et al., 1990) using the same animals and experimental protocols.

\section{Animals and treatments}

Oestrus was synchronized in mature Angora $\times$ Cashmere female goats with intravaginal progestagenimpregnated sponges (Repromap; Upjohn Pty Ltd, Melbourne, Australia) and animals were randomly assigned to one of three treatment groups: group 1 was given 1200 iu PMSG (Pregnecol; Heriot Agvet, Melbourne, Australia) intramuscularly $48 \mathrm{~h}$ before sponge withdrawal; group 2 was given $12 \mathrm{mg}$ ovine FSH (Embryo Plus; Hamilton Artificial Breeders, Victoria, Australia) administered intramuscularly in consecutive doses of 3,3,2,2,1 and $1 \mathrm{mg}$ at intervals of $12 \mathrm{~h}$, starting $48 \mathrm{~h}$ before sponge withdrawal; and group 3 were control animals receiving no exogenous gonadotrophins. Ovulation was synchronized in gonadotrophin-treated animals by injecting 750 iu human chorionic gonadotrophin (hCG; Chorulon; Intervet, Lyppard Chemical Co., Melbourne, Australia) intramuscularly $20 \mathrm{~h}$ after sponge withdrawal and in control animals at detection of oestrus, which commenced $36-41 \mathrm{~h}$ after sponge withdrawal.

\section{Experiments}

Ovaries were removed from animals in each treatment group at one of three times: (i) at sponge withdrawal, (ii) $20 \mathrm{~h}$ after sponge withdrawal and (iii) $18 \mathrm{~h}$ after the hCG injection. Intact nonatretic follicles were dissected from each ovary at room temperature in Dulbecco's phosphate-buffered saline (PBS), supplemented with bovine serum albumin (BSA), pyruvate, lactate, glucose and antibiotics as described previously (Kumar $e t$ al., 1990). Only healthy follicles $>3 \mathrm{~mm}$ in diameter were studied from gonadotrophin-treated animals at the time of sponge withdrawal and $20 \mathrm{~h}$ later; but $18 \mathrm{~h}$ after hCG, only those measuring $\geqslant 5 \mathrm{~mm}$ were analysed. In each control animal, there were only one or two large healthy follicles present at each time and these measured $>5 \mathrm{~mm}$ in diameter.

\section{Collection of follicular fluid from individual follicles and measurement of steroid concentrations}

After measuring the diameter of cleanly dissected follicles with a $1 \mathrm{~mm}$ division scale, each follicle was transferred to a small sterile Petri dish (tissue culture dishes; Disposable Products, South Australia) containing $1.5 \mathrm{ml}$ of BSA-free dissecting medium and incised with fine scissors to release the follicular fluid. The collapsed follicular wall was then removed and placed in a separate Petri dish containing medium supplemented with BSA. The attached cumulusoocyte complex was dissected from the thecal wall, the degree of cumulus expansion noted, and the nuclear and cytoplasmic maturational status of the oocyte determined as outlined below.

The medium containing follicular fluid was centrifuged at $800 \mathrm{~g}$ for $5 \mathrm{~min}$ to remove cellular debris and the supernatant stored at $-80^{\circ} \mathrm{C}$ before analysis of oestradiol and progesterone by radioimmunoassay. Since each follicular fluid sample was collected in a standard volume of PBS, the radioimmunoassay results reflected steroid concentrations in diluted follicular fluid. To calculate the concentration of oestradiol and progesterone in the original follicular fluid, the volume of each follicle was estimated using the standard relationship between the diameter $(d)$ measured for each follicle at dissection and the volume $(V)$ of a sphere, whereby $V=4 / 3 \times \pi \times(d / 2)^{3}$.

The radioimmunoassays were conducted using test kits purchased from Farmos Diagnostica (Australian Lab. Services, Melbourne, Australia). These are designed for human serum, and therefore required validation for use with diluted goat follicular fluid.

\section{Oestradiol assay}

The antiserum to oestradiol was raised in rabbits against oestradiol-6-carboxymethoxylamine-BSA and crossreacts with 16-oxoestradiol $(4 \cdot 1 \%)$, oestrone $(1 \cdot 16 \%)$ and some other steroids $(<1 \%)$. Lyophilized human serum 
standards containing $0 \cdot 0,0 \cdot 05,0 \cdot 15,0 \cdot 5,1 \cdot 5,5 \cdot 0$ and $15 \cdot 0 \mathrm{nmol}$ oestradiol $1^{-1}$ after reconstitution with distilled water were used for generating the standard curve. The assay was conducted essentially as described in the kit but using volumes of reagents which were $30 \%$ of those recommended. Follicular fluid samples, where appropriate, were diluted 2-1000-fold with PBS before assay.

The kit was validated for use with goat follicular fluid by first dissolving crystalline oestradiol (1,3,5[10]estratriene-3,17 $\beta$-diol; Sigma Chemical Co., St Louis, USA) in absolute ethanol (Analytical Reagent; Ajax Chemicals, NSW, Australia). After evaporation of appropriate volumes in $10 \times 75 \mathrm{~mm}$ borosilicate glass tubes (Borex; Chase Instruments, Vermont, USA) and reconstitution with oestradiol-free follicular fluid, standard concentrations of $0 \cdot 0$, $0 \cdot 5,0.75,1 \cdot 5,2 \cdot 5,5 \cdot 0$ and $15.0 \mathrm{nmol} 1^{-1}$ were obtained. The resulting standard curve showed parallelism with that generated by the kit standards in the same assay (Fig. 1a). Furthermore, the curve of serial dilution of a sample of follicular fluid with a high concentration of oestradiol also demonstrated parallelism with the standard curve obtained using the kit standards (Fig. Ib). The interassay coefficient of variation between four assays was 10.9 and $5.9 \%$ for two samples of follicular fluid containing 378.2 and $4202.9 \mathrm{nmol}$ oestradiol $\mathrm{l}^{-1}$, respectively. The corresponding intraassay coefficient of variation for these two samples determined by assaying 12 times in one assay was $9 \cdot 1$ and $8.5 \%$, respectively. The sensitivity of the assay was $<0.05 \mathrm{nmol} 1^{-1}$.
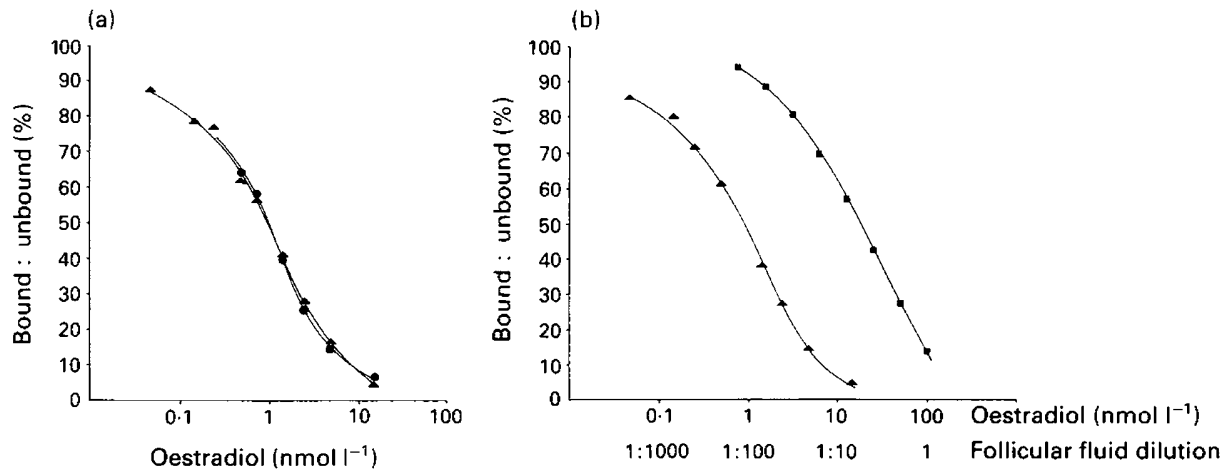

Fig. 1. Displacement curves demonstrating parallelism between oestradiol standards in the assay kit ( $\mathbf{\Delta}$ ) and (a) prepared oestradiol standards (O), (b) serial dilution of a sample of follicular fluid with a high concentration of oestradiol $(\boldsymbol{a})$. Comparison of the coefficient of regression of the two curves (Armitage \& Berry, 1987) showed that they were not significantly different: (a) kit standards: -2.11 versus prepared standards: $-1.91, P>0.05$; (b) kit standards: -45.64 versus follicular fluid: $-41 \cdot 20, P>0.05$.

\section{Progesterone assay}

The antiserum to progesterone was raised in rabbits against $11 \alpha$-hydroxyprogesterone-hemisuccinate-BSA and crossreacts with $11 \beta$-hydroxyprogesterone $(75 \%), 5 \alpha$-dihydroprogesterone $(8 \cdot 8 \%), 5 \beta$-dihydroprogesterone $(7 \cdot 1 \%)$ and $<1 \%$ for all other steroids tested. The kit standards were lyophilized human sera which, after reconstitution with distilled water, gave concentrations of $0 \cdot 0,1 \cdot 0,2 \cdot 5,10,25$ and $100 \mathrm{nmol}^{-1}$. The assay was conducted as described in the kit except that $40 \%$ of the recommended volumes of reagents were used. Where appropriate, samples of follicular fluid were diluted 2-1000 fold with PBS before assay.

Validation of the kit for use with goat follicular fluid was conducted as outlined in the oestradiol assay, using crystalline progesterone (4-pregnene-3,20-dione; Sigma Chemical Co., St Louis, USA) dissolved in progesterone-free follicular fluid to obtain the following concentrations: $0 \cdot 0,0 \cdot 5,1 \cdot 0,2 \cdot 5,10 \cdot 0,25$ and $100 \mathrm{nmol}^{-1}$. When these samples were assayed alongside the standards in the kit in the same assay, parallelism was obtained between the two standard curves (Fig. 2a). In addition, the curve of serial dilution of a sample of follicular fluid with a high level of progesterone also showed parallelism with the standard curve generated with the kit-standards (Fig. 2b). The interassay coefficient of variation between four assays for three follicular fluid samples containing $302.3,780.1$ and $2228.2 \mathrm{nmol}$ progesterone $1^{-1}$ was $10 \cdot 6,12 \cdot 3$ and $9 \cdot 1 \%$, respectively. The corresponding intraassay coefficient of variation determined by assaying 10 times in a single assay was $15 \cdot 6,15 \cdot 1$ and $10 \cdot 4 \%$, respectively. The sensitivity of the assay was approximately $0.5 \mathrm{nmol}^{-1}$.

\section{Radiolabelling and assessment of the meiotic status of each individual oocyte}

The cumulus-oocyte complex from each follicle was incubated separately at $37^{\circ} \mathrm{C}$ for $3 \mathrm{~h}$ in $25 \mu \mathrm{l}$ of antibiotic-free

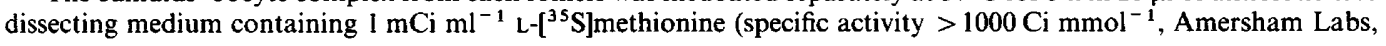



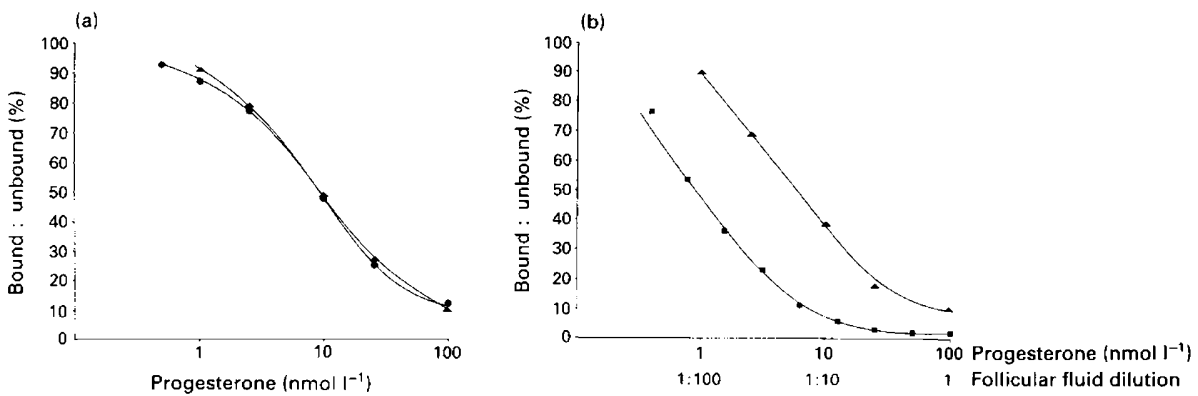

Fig. 2. Displacement curves demonstrating parallelism between progesterone standards in the assay kit $(\mathbf{\Delta})$ and (a) prepared progesterone standards $(\mathbf{O})$, (b) serial dilution of a sample of follicular fluid with a high concentration of progesterone ( $\mathbf{a})$. Comparison of the coefficient of regression of the two curves (Armitage \& Berry, 1987) showed that they were not significantly different: (a) kit standards: -2.35 versus prepared standards: $-2.54, P>0.05$; (b) kit standards: $-51 \cdot 15$ versus follicular fluid: $-47.54, P>0.05$.

Buckinghamshire, UK), essentially as described by Moor et al. (1981). Each labelled complex was then washed once in fresh dissecting medium and denuded of cumulus cells by repeated pipetting. To facilitate removal of the cells when cumulus expansion had occurred, the complex was placed in a small volume of dissecting medium containing $500 \mathrm{iu}$ $\mathrm{ml}^{-1}$ ovine hyaluronidase (Sigma Chem. Co., St Louis, USA) for 1-2 min.

The meiotic status of each oocyte was then determined using a fluorescent deoxyribonucleic acid (DNA)-binding dye, 4'-6-diamidino-2-phenylindole (DAPI; Sigma Chemical Co., St Louis, USA) as described by Kumar et al. (1990). Oocytes were classified as either (i) germinal vesicle I (GVI - chromatin loosely dispersed within the nucleus), (ii) germinal vesicle II (GVII - chromatin condensed into distinct clumps within an intact nuclear membrane), (iii) metaphase I (MI - a spot of condensed chromatin present at the periphery of the oocyte in the absence of a germinal vesicle and first polar body) or (iv) metaphase II (MII - similar to MI but with the fluorescence in the first polar body clearly identifiable).

Each denuded oocyte was then briefly washed in $10 \mathrm{mmol}$ Tris $\mathrm{HCl}^{-1}$ (trizma hydrochloride, reagent grade, Sigma Chemical Co., St Louis, USA) pH 7.4 and collected in a small volume of Tris buffer. After lyophilization, $25 \mu \mathrm{l}$ of sodium dodecyl sulfate (SDS; BDH Chem. Ltd, Poole, UK) buffer (O'Farrell, 1975) was added and the samples frozen at $-80^{\circ} \mathrm{C}$ until required for electrophoresis.

\section{Electrophoretic analysis of individual oocyte proteins}

Labelled oocytes were prepared for electrophoresis by thawing the samples and then heating for $1 \mathrm{~min}$ at $100^{\circ} \mathrm{C}$. The quantity of labelled methionine incorporated into protein was determined by trichloroacetic acid precipitation of a $5 \mu \mathrm{l}$ aliquot. An equal amount of radioactivity for each oocyte was then applied to each track of an $8-15 \%$ linear gradient sodium dodecyl sulfate (SDS) polyacrylamide slab gel and the poiypeptides separated for $3 \mathrm{~h}$ at a constant current of $20 \mathrm{~mA}$ per gel, as described by Moor et al. (1981). Gels were then fixed, impregnated with 2,5-diphenyl oxazole (PPO; United Technologies, Packard, Illinois, USA), dried under vacuum and exposed to Fuji RX X-ray film at $-80^{\circ} \mathrm{C}$ (Bonner \& Laskey, 1974; Laskey \& Mills, 1975). Molecular weight determinations were made using the following as standards: phosphorylase $b(94 \mathrm{kDa})$, bovine serum albumin $(67 \mathrm{kDa})$, ovalbumin $(43 \mathrm{kDa})$, carbonic anhydrase (30 kDa), soybean trypsin inhibitor (20.1 kDa) and lysozyme (14.4 kDa) (Bio-Rad Labs, Richmond, CA, USA).

\section{Statistical analysis}

The mean concentration of oestradiol and progesterone in follicular fluid between gonadotrophin-treated and control animals at the different times were compared using Student's $t$ test.

\section{Results}

\section{Concentration of steroids in follicular fluid}

Oestradiol. At the time of sponge withdrawal, there was no significant difference in the mean concentration of oestradiol in follicular fluid from FSH-treated and control animals (Table 1). By 


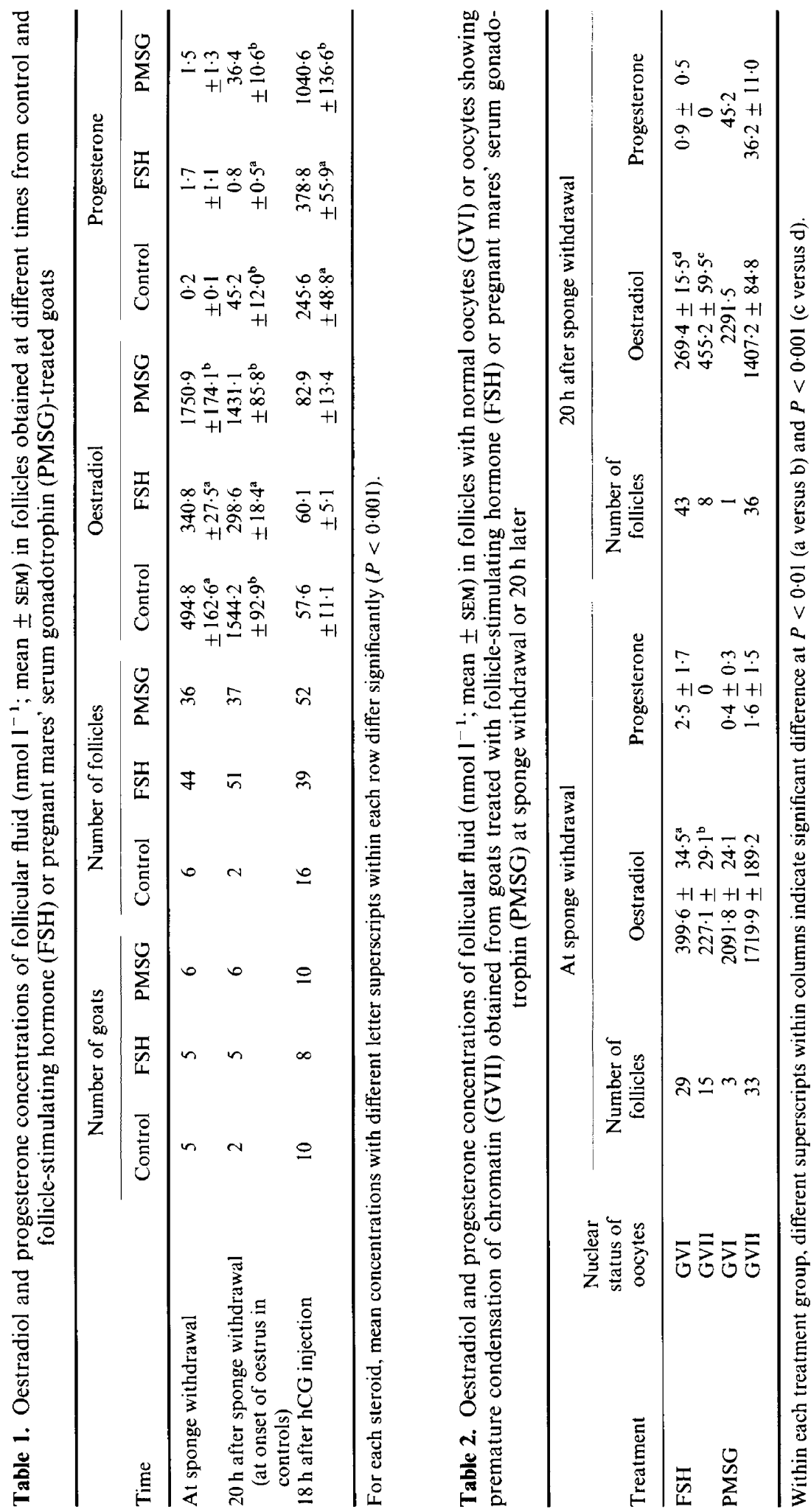


contrast, the mean concentration in PMSG-treated animals was significantly higher than in the other two treatment groups. At $20 \mathrm{~h}$ after sponge withdrawal, mean oestradiol concentrations in follicular fluid from FSH- and PMSG-treated animals were unchanged from those observed at the time of sponge withdrawal (FSH: 298.6 versus $340.8 \mathrm{nmol} \mathrm{l}^{-1}, t=1 \cdot 3, P<0 \cdot 2$; PMSG: $1431 \cdot 1$ versus $1750.9 \mathrm{nmol} \mathrm{1}^{-1}, t=1 \cdot 7, P<0 \cdot 2$ ). However, a significant increase occurred in control animals at the onset of oestrus $\left(1544.2\right.$ versus $\left.494.8 \mathrm{nmol}^{-1}, t=3.5, P<0.02\right)$, such that the mean oestradiol concentration was equivalent to that observed in PMSG-treated animals $20 \mathrm{~h}$ after sponge withdrawal. At $18 \mathrm{~h}$ after administration of $\mathrm{hCG}$, there was a marked decrease in oestradiol in follicular fluid in all three treatment groups and the mean concentrations were not significantly different.

Progesterone. Progesterone was not detected in follicular fluid in most follicles from all three treatment groups at the time of sponge withdrawal (Table 1). Moreover, at $20 \mathrm{~h}$ after sponge withdrawal, most follicles in the FSH-treated group (47 of 51) still had undetectable amounts of progesterone. By contrast, 18 out of 37 follicles in the PMSG-treated group had measurable amounts of progesterone (range: $4 \cdot 8-304 \cdot 4 \mathrm{nmol} \mathrm{1}^{-1}$ ), with the overall mean concentration being significantly higher than that at sponge withdrawal $\left(36.4\right.$ versus $\left.1.5 \mathrm{nmol}^{-1}, t=13.7, P<0.001\right)$, and to that in the FSH group. Progesterone was present in both follicles sampled in the control group at the onset of oestrus. Their mean concentration was significantly higher than control follicles at the time of sponge withdrawal $\left(45.2\right.$ versus $\left.0.2 \mathrm{nmol}^{-1}, t=7 \cdot 9, P<0.001\right)$, and was comparable to that seen in follicular fluid from PMSG-treated animals $20 \mathrm{~h}$ after sponge withdrawal. At $18 \mathrm{~h}$ after hCG injection, high amounts of progesterone were present in follicular fluid from all three treatment groups. However, although the mean concentrations were comparable between control and FSH-treated animals, a significantly higher mean content was seen in the PMSG-treated group.

\section{Follicular fluid steroid concentrations and meiotic status of oocytes}

Significantly more oocytes from PMSG-treated, compared with FSH-treated, animals showed premature condensation of chromatin within an intact nucleus both at the time of sponge withdrawal and $20 \mathrm{~h}$ later (Kumar et al., 1990). In the present study, anomalies in follicular fluid steroid concentrations in follicles from PMSG-treated animals were also observed at both these times. To determine whether these abnormalities were correlated, we classified follicles within each treatment group according to the meiotic status of their oocytes (i.e. GVI or GVII), and compared their mean follicular fluid concentration of oestradiol and progesterone (Table 2). We have not analysed follicles removed $18 \mathrm{~h}$ after $\mathrm{hCG}$, since by this time most oocytes had undergone germinal vesicle breakdown and there was no significant difference in the proportion at MI-MII between these two treatment groups.

In the FSH-treated group at the time of sponge withdrawal, the mean oestradiol concentration in follicles with a normal GVI oocyte was significantly higher than in those with a GVII oocyte. However, the situation was reversed $20 \mathrm{~h}$ later, when follicles containing GVII oocytes had a significantly higher mean content. In the PMSG-treated group, at both times, a higher mean oestradiol concentration was observed in follicles containing GVI oocytes than follicles with GVII oocytes. However, the small number of GVI oocytes precludes any valid statistical comparison between the two types of follicle in this treatment group. There was no difference in the mean concentration of progesterone between the two types of follicle within each treatment group at both time points, even though follicles from PMSG-treated animals had a significantly higher mean content $20 \mathrm{~h}$ after sponge withdrawal.

These results, therefore, suggest that even though high amounts of intrafollicular steroids in PMSG-treated animals are associated with an increased incidence of premature condensation of chromatin in oocytes, the two events are not causally related. 


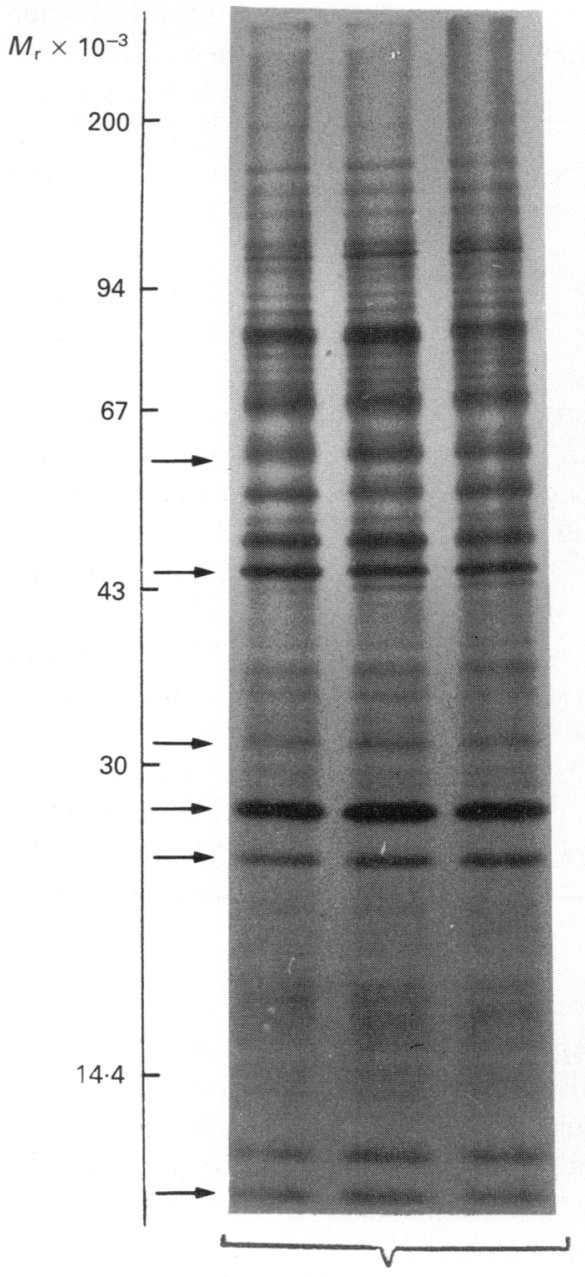

(a)

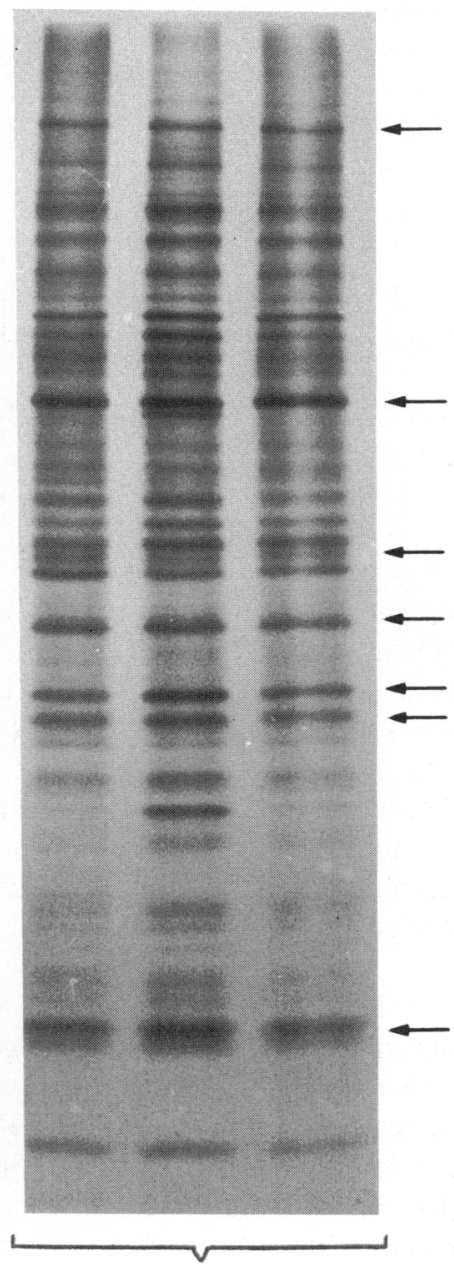

(b)

Fig. 3. Fluorographs of $\left[{ }^{35}\right.$ S $]$ methionine-labelled polypeptides from individual goat oocytes separated on an 8-15\% linear gradient sodium dodecyl sulfate polyacrylamide gel: (a) protein synthesis profiles before the initiation of maturation (germinal vesicle oocyte); (b) proteins synthesized by oocytes after undergoing germinal vesicle breakdown in vivo after administration of human chorionic gonadotrophin (metaphase I or II). Arrows indicate the protein bands referred to in text.

\section{Cytoplasmic maturation of oocytes}

The pattern of protein synthesis in oocytes of sheep, which reflects their cytoplasmic maturational status, is closely related to their meiotic status (Crosby et al., 1981; Osborn \& Moor, 1983b). Oocytes that are at the germinal vesicle stage showed an unchanged or prematurational pattern of protein synthesis on a one-dimensional SDS polyacrylamide gel, whereas a changed or post-maturational pattern was characteristic of oocytes that had undergone germinal vesicle breakdown to either metaphase I or II.

We used a similar classification based on one-dimensional patterns of protein synthesis to assess the cytoplasmic maturational status of individual oocytes. The two standard profiles 
Table 3. Analysis of the patterns of protein synthesis in oocytes obtained from control and folliclestimulating hormone (FSH)- or pregnant mares' serum gonadotrophin (PMSG)-treated goats at sponge withdrawal or $20 \mathrm{~h}$ later

\begin{tabular}{|c|c|c|c|c|c|c|}
\hline \multirow[b]{3}{*}{ Treatment } & \multirow{3}{*}{$\begin{array}{c}\text { Number } \\
\text { of } \\
\text { goats }\end{array}$} & \multirow{3}{*}{$\begin{array}{c}\text { Number of oocytes } \\
\text { labelled and } \\
\text { assessed }\end{array}$} & \multicolumn{4}{|c|}{ Protein synthesis profile } \\
\hline & & & \multicolumn{3}{|c|}{$\begin{array}{l}\text { Prematuration pattern } \\
\text { (compact cumulus) }\end{array}$} & \multirow{2}{*}{$\begin{array}{c}\text { Post-maturation pattern } \\
\text { (expanded cumulus) } \\
\text { MI-MII }\end{array}$} \\
\hline & & & GVI & GVII & MI-MII & \\
\hline \multicolumn{7}{|c|}{ At sponge withdrawal } \\
\hline Control & 5 & 6 & $\begin{array}{c}5 \\
(83 \cdot 3 \%)\end{array}$ & 0 & 0 & $\begin{array}{c}1 \\
(16 \cdot 7 \%)\end{array}$ \\
\hline FSH & 5 & 44 & $\begin{array}{c}29 \\
(65.9 \%)\end{array}$ & $\begin{array}{c}15 \\
(34 \cdot 1 \%)\end{array}$ & 0 & 0 \\
\hline PMSG & 6 & 38 & $\begin{array}{c}3 \\
(7 \cdot 9 \%)\end{array}$ & $\begin{array}{c}34 \\
(89 \cdot 5 \%)\end{array}$ & 0 & $\begin{array}{c}1 \\
(2 \cdot 6 \%)\end{array}$ \\
\hline \multicolumn{7}{|c|}{$\begin{array}{l}20 \mathrm{~h} \text { after sponge withdrawal } \\
\text { (at onset of oestrus in controls) }\end{array}$} \\
\hline Control & 2 & 2 & $\begin{array}{c}2 \\
(100 \%)\end{array}$ & 0 & 0 & 0 \\
\hline FSH & 5 & 54 & $\begin{array}{c}43 \\
(79 \cdot 6 \%)\end{array}$ & $\begin{array}{c}8 \\
(14 \cdot 8 \%)\end{array}$ & $\begin{array}{c}1 \\
(1.9 \%)\end{array}$ & $\begin{array}{c}2 \\
(3 \cdot 7 \%)\end{array}$ \\
\hline PMSG & 6 & 39 & $\begin{array}{c}1 \\
(2 \cdot 5 \%)\end{array}$ & $\begin{array}{c}34 \\
(87 \cdot 2 \%)\end{array}$ & $\begin{array}{c}4 \\
(10 \cdot 3 \%)\end{array}$ & 0 \\
\hline
\end{tabular}

(Fig. 3), which indicate normal pre- and post-maturational patterns of protein synthesis, are distinctly different from each other and closely resemble the standard profiles reported in sheep (see Fig. 4 in Osborn et al., 1986). These profiles confirm that maturation of goat oocytes in vivo is accompanied by major changes in the pattern of protein synthesis that involve a substantial increase in incorporation into some polypeptides and a reduction into others. Among the most notable of polypeptides that are visible before maturation, but which become greatly reduced during maturation, are those with molecular weights of $10 \cdot 0,25 \cdot 0,27 \cdot 0,31 \cdot 0,45 \cdot 0$ and $59 \cdot 0 \mathrm{kDa}$ (Fig. 3). By contrast, a number of 'new' proteins appear after the onset of maturation, the most prominent ones having molecular weights of $17 \cdot 0,33 \cdot 0,35 \cdot 0,40 \cdot 0,47 \cdot 0,67 \cdot 0$ and $119 \cdot 0 \mathrm{kDa}$. With a few exceptions, most of these changes in polypeptides (indicated by arrows in Fig. 3) occur at molecular weights that are similar to those reported previously in sheep oocytes (Osborn et al., 1983b).

At each time point, the oocyte within each follicle in each treatment group was classified according to meiotic status and protein synthesis profile. The results (Table 3) show that, despite differences among the three treatment groups in the proportion of oocytes with premature chromatin condensation (GVII oocytes) both at the time of sponge withdrawal and $20 \mathrm{~h}$ later, most oocytes in each group displayed a characteristic pre-maturational pattern of protein synthesis (Fig. 4). A post-maturational pattern was observed only in four oocytes, and in each case, germinal vesicle breakdown had occurred together with expansion of the cumulus mass. All of these oocytes came from follicles with intrafollicular concentrations of oestradiol and progesterone comparable to those observed in follicles close to ovulation (compare with Table 1). Surprisingly, at $20 \mathrm{~h}$ after sponge withdrawal, four out of 10 follicles from one animal in the PMSG group and one follicle from an FSH-treated animal contained oocytes at the MI-MII stage, even though the cumulus had not expanded and the pattern of protein synthesis remained unchanged. However, in all these follicles, the oestradiol and progesterone concentrations were comparable to the mean content in follicles containing GVI and GVII oocytes at this time. 

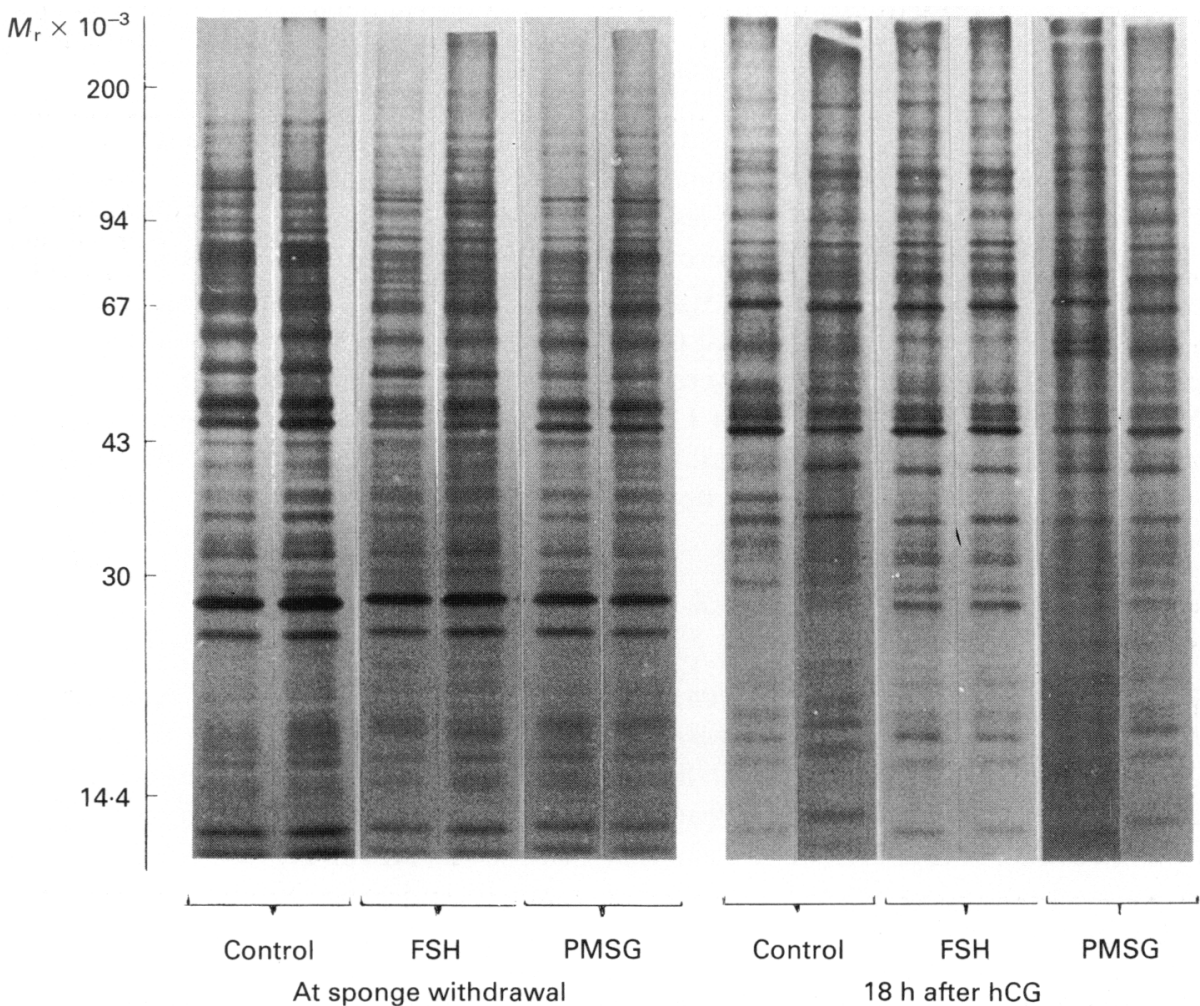

Fig. 4. Protein synthesis profiles of individual oocytes obtained from unstimulated (control) and follicle-stimulating hormone (FSH)- or pregnant mares' serum gonadotrophin (PMSG)treated goats at sponge withdrawal or $18 \mathrm{~h}$ after human chorionic gonadotrophin $(\mathrm{hCG})$ injection.

Table 4. Analysis of the patterns of protein synthesis in oocytes obtained from control and folliclestimulating hormone (FSH)- or pregnant mares' serum gonadotrophin (PMSG)-treated goats $18 \mathrm{~h}$ after human chorionic gonadotrophin injection

\begin{tabular}{|c|c|c|c|c|c|c|c|}
\hline \multirow[b]{4}{*}{ Treatment } & \multirow{4}{*}{$\begin{array}{c}\text { Number } \\
\text { of } \\
\text { goats }\end{array}$} & \multirow{4}{*}{$\begin{array}{l}\text { Number of } \\
\text { oocytes } \\
\text { labelled } \\
\text { and } \\
\text { assessed }\end{array}$} & \multicolumn{5}{|c|}{ Protein synthesis profile } \\
\hline & & & \multicolumn{4}{|c|}{$\begin{array}{c}\text { Prematuration pattern } \\
\text { Cumulus }\end{array}$} & \multirow{3}{*}{$\begin{array}{c}\text { Post-maturation pattern } \\
\text { Cumulus } \\
\text { expanded } \\
\text { MI-MII }\end{array}$} \\
\hline & & & \multicolumn{2}{|c|}{ compact } & \multicolumn{2}{|c|}{ expanded } & \\
\hline & & & GVIl & MI MII & GVI & GVII & \\
\hline Control & 10 & 15 & 0 & $\begin{array}{c}1 \\
(6 \cdot 7 \%)\end{array}$ & 0 & 0 & $\begin{array}{c}14 \\
(93 \cdot 3 \%)\end{array}$ \\
\hline FSH & 8 & 46 & $\begin{array}{c}4 \\
(8 \cdot 7 \%)\end{array}$ & 0 & $\begin{array}{c}2 \\
(4 \cdot 3 \%)\end{array}$ & $\begin{array}{c}2 \\
(4 \cdot 3 \%)\end{array}$ & $\begin{array}{c}38 \\
(82 \cdot 7 \%)\end{array}$ \\
\hline PMSG & 10 & 59 & $\begin{array}{c}2 \\
(3 \cdot 4 \%)\end{array}$ & $\begin{array}{c}4 \\
(6 \cdot 8 \%)\end{array}$ & 0 & $\begin{array}{c}1 \\
(1.7 \%)\end{array}$ & $\begin{array}{c}52 \\
(88 \cdot 1 \%)\end{array}$ \\
\hline
\end{tabular}

At $18 \mathrm{~h}$ after injection of hCG, most follicles in all three treatment groups had low oestradiol and high progesterone concentrations, and contained oocytes that displayed a post-maturational protein pattern (Fig. 4) associated with germinal vesicle breakdown and cumulus expansion 
(Table 4). There were, however, a number of discrepancies. First, $20 \mathrm{~h}$ after sponge withdrawal, four oocytes from two PMSG-treated animals and a single oocyte from one control animal were at the MI-MII stage despite an intact cumulus and unchanged pattern of protein synthesis. In all cases, intrafollicular oestradiol concentrations were still the same as at $20 \mathrm{~h}$, but progesterone was increased only in one PMSG follicle. Similarly, oestradiol remained high in six follicles (four: FSH; two: PMSG) that contained GVII oocytes with prematurational protein profiles and a compact cumulus, although conversely, progesterone was only increased in the follicles from the FSHtreated animals. Second, a number of oocytes (four: FSH; one: PMSG) were recovered with an intact germinal vesicle and an unchanged protein profile but in an expanded cumulus mass. Intrafollicular progesterone concentrations were comparable to those expected at $18 \mathrm{~h}$ after hCG, but in the PMSG follicle and in two out of four FSH follicles, oestradiol concentrations were comparable to those at $20 \mathrm{~h}$ after sponge withdrawal. It is clear, therefore, that in these follicles the administration of hCG had induced changes in steroidogenesis and cumulus expansion without activating oocyte maturation.

\section{Discussion}

We have shown that follicular steroidogenesis in vivo during superovulation of goats with PMSG is abnormal compared with steroidogenesis in unstimulated and FSH-treated animals. These abnormalities consisted of higher intrafollicular concentrations of oestradiol at the time of sponge withdrawal and, compared with FSH-treated animals, higher amounts of both oestradiol and progesterone $20 \mathrm{~h}$ later. Moreover, it is clear that PMSG-treated follicles were primed to produce greater amounts of progesterone, since significantly higher progesterone concentrations were detected in these follicles $18 \mathrm{~h}$ after hCG injection than in pre-ovulatory follicles from unstimulated and FSH-treated animals. Our results, therefore, support the observation by Moor et al. (1985) that the pattern of oestradiol and progesterone secretion by cultured follicles obtained from sheep superovulated with PMSG was grossly perturbed compared to follicles derived from unstimulated and FSH-treated animals.

The mechanism by which PMSG disturbs follicular steroidogenesis in vivo is unknown. It is possible that the predominant luteinizing hormone ( $\mathrm{LH}$ )-like activity in PMSG (Farmer \& Papkoff, 1979; Henderson et al., 1990) initially activates the theca interna in follicles recruited for growth to synthesize increased amounts of androgen precursors. The high content of oestradiol in follicular fluid observed within $48 \mathrm{~h}$ of treatment may then result from the rapid conversion of these precursors by the aromatase enzyme system in the granulosa cells. Furthermore, the prolonged half-life of PMSG (McIntosh et al., 1975; Schams et al., 1978) together with the ability of oestradiol to enhance the responsiveness of granulosa cells to FSH (Richards, 1980) would allow the stimulated follicles to continue producing excessive amounts of oestradiol. This would account for the high concentration of oestradiol still present in follicles $20 \mathrm{~h}$ after sponge withdrawal. The need for follicles to be primed with oestradiol before FSH can increase the number of LH receptors (Richards, 1980) may explain why PMSG-treated follicles produced increased amounts of progesterone only later during superovulation. Moreover, the induction of a larger number of LH receptors in these follicles would enable them to respond more completely to a standard dose of $\mathrm{hCG}$, resulting in significantly higher intrafollicular concentrations of progesterone $18 \mathrm{~h}$ later.

The significance of steroids in the maturation of mammalian oocytes has been highlighted (Soupart, 1974; Thibault, 1977; Moor \& Trounson, 1977; McGaughey, 1977; Moor, 1978). In particular, altering the profile of steroids secreted by pre-ovulatory sheep follicles during in vitro maturation results in anomalies in both the nuclear and cytoplasmic maturation of oocytes that lead to problems at fertilization (Moor et al., 1980; Osborn \& Moor, 1983a; Osborn et al., 1986). Furthermore, it is well documented that disturbances in the normal endocrine milieu occur during superovulation with PMSG (Booth et al., 1975; Jensen et al., 1982; Armstrong et al., 1983; Callesen et al., 1986), and that this gonadotrophin induces premature activation of oocyte maturation in 
sheep and cattle (Moor et al., 1985; Callesen et al., 1986). Although an association between abnormalities in follicular steroidogenesis and derangements in oocyte maturation may be inferred from these studies, a direct cause and effect relationship between these two events has yet to be established in vivo. In our study, we have addressed this issue by relating the nuclear and cytoplasmic maturational status of individual oocytes to the steroid concentration of their follicular fluid after superovulation. Our results show that while there is a definite association between abnormalities in follicular steroidogenesis and anomalies in nuclear maturation after superovulation of goats with PMSG, the two events occur independently and are not causally related.

We have also demonstrated in this study that, despite inducing abnormalities in follicular steroidogenesis and the timing of nuclear maturation, PMSG treatment does not result in the premature activation of cytoplasmic maturation in oocytes either at the time of sponge withdrawal or $20 \mathrm{~h}$ later. This is contrary to the observation of Moor et al. (1985), where $28 \%$ of follicles obtained from PMSG-treated sheep and cultured for $21 \mathrm{~h}$ in vitro contained oocytes in which cytoplasmic maturation had been activated. This discrepancy may be explained by differences in the experimental design and methodologies used in the two studies. In the study by Moor et al. (1985), sheep follicles were obtained $40 \mathrm{~h}$ after PMSG treatment (which corresponds to the time of sponge withdrawal in our study) and were cultured for $21 \mathrm{~h}$ before the profiles of protein synthesis in oocytes were analysed. However, neither the cytoplasmic nor the meiotic status of these oocytes were determined before follicle culture. Nevertheless, other publications from this group have shown that oocytes from PMSG-treated sheep at the time of follicle isolation have an intact germinal vesicle and an unchanged prematurational pattern of protein synthesis (Moor \& Trounson, 1977; Osborn \& Moor, 1983b). Our results also show that the pattern of protein synthesis in goat oocytes examined $48 \mathrm{~h}$ after gonadotrophin treatment is unchanged irrespective of the occurrence of premature chromatin condensation. However, after an additional $20 \mathrm{~h}$ of in vivo 'culture', which is equivalent to the $21 \mathrm{~h}$ in vitro culture used by Moor et al. (1985), goat oocytes still retained the same cytoplasmic and meiotic status. Indeed, cytoplasmic maturation in most of these oocytes was observed only when hCG was administered in vivo, or after oocytes were removed from the follicles and cultured in vitro (data not shown). It is possible therefore that, in a neutral culture environment, changes induced by PMSG in vivo become apparent in vitro, whereas the preservation of ovarian integrity in vivo maintains the normal paracrine and autocrine regulation of follicular function that sustains the inhibitory influence of the follicle on oocyte maturation.

Nevertheless, it is clear that PMSG can still induce premature chromatin condensation in goat oocytes in vivo without germinal vesicle breakdown, although the mechanism of action is uncertain. It has been proposed that chromatin condensation may require only partial activation of the maturation-promoting factor (MPF) in oocytes, whereas its full activation is a prerequisite for nuclear membrane breakdown (Kubelka et al., 1988). Thus the LH-like activity of PMSG may activate MPF only partially and induce chromatin condensation without further maturational change. There is some evidence to support this hypothesis. First, we have shown that increasing the level of $\mathrm{LH}$ bioactivity during superovulation of goats with FSH, through the administration of subovulatory doses of $\mathrm{hCG}$, resulted in chromatin condensation without nuclear membrane breakdown (Kumar et al., 1991). Second, Bomsel-Helmreich et al. (1989) have found that low doses of hCG initiated chromatin condensation and not germinal vesicle breakdown in rabbit oocytes, whereas with increasing doses of hCG, more advanced stages of nuclear maturation occurred. Third, we have not observed the synthesis of a protein analagous to the $47 \mathrm{kDa}$ ' $\mathrm{m}$ ' protein which appears in sheep oocytes immediately before germinal vesicle breakdown (Moor \& Crosby, 1986).

We therefore challenge the hypothesis proposed by Moor et al. (1985) that PMSG causes premature activation of cytoplasmic maturation in vivo and that this results in abnormally 'aged' oocytes at ovulation. However, it is possible that the abnormalities in follicular steroidogenesis associated with PMSG treatment may affect cytoplasmic maturation in oocytes and result in anomalies at fertilization. 
The results of this study have also confirmed previous observations on the uncoupling of the events that occur during oocyte maturation (Moor et al., 1981; Osborn et al., 1986). As in the sheep, a changed pattern of protein synthesis was seen only in goat oocytes at the metaphase 1 or II stages of meiosis after germinal vesicle breakdown and was associated with expansion of the cumulus mass and with low oestradiol and high progesterone concentrations in the follicular fluid. However, in a number of follicles, a dissociation between these maturational events was observed. For example, despite undergoing germinal vesicle breakdown, some oocytes still showed an unchanged prematurational pattern of protein synthesis associated with an unexpanded cumulus mass. It is likely that these oocytes are blocked at the early MI stage of meiosis since the major changes in protein synthesis associated with cytoplasmic maturation occur only after the oocytes have reached MI (Moor \& Gandolfi, 1987). In other instances, cumulus expansion was seen in oocytes in which neither nuclear nor cytoplasmic maturation had been activated. With a few exceptions, oestradiol and progesterone concentrations in the follicular fluid in all these cases were typical of follicles before the onset of maturation. It is thus clear that whereas oocyte maturation in goats is characterized by an orderly sequence of changes in the follicle and the cumulus-oocyte complex, some of these events can occur independently.

In conclusion, we have shown that the production of oestradiol and progesterone by ovarian follicles is markedly increased during superovulation of goats with PMSG. Nevertheless, these disturbances in follicular steroidogenesis were not causally related to the high incidence of oocytes undergoing premature condensation of chromatin in PMSG-treated animals. We have yet to determine whether this apparent abnormality in the timing of meiotic maturation compromises the fertilization of oocytes. However, this appears unlikely since most oocytes underwent germinal vesicle breakdown following the administration of hCG, with the proportion progressing to $\mathrm{MI}-$ MII being similar in unstimulated and gonadotrophin-treated animals. Moreover, cytoplasmic maturation did not appear to be grossly perturbed during superovulation with gonadotrophins. It is still possible that PMSG may reduce fertilization rates through the enhanced production of steroids in the peri-ovulatory period and the postulated disturbance in gamete transport in the reproductive tract (Robinson, 1973; Trounson \& Moore, 1974; Crisman et al., 1980; Evans \& Armstrong, 1984). Alternatively, PMSG may induce subtle abnormalities in the cytoplasmic maturation of goat oocytes that cannot be detected on one-dimensional protein gels but which compromise their fertilization or subsequent embryonic development.

This work was supported by Embryotechnology Australia Pty Ltd. We thank P. Batt for assistance in preparing the animals. J. Kumar is a recipient of an NH and MRC postgraduate research scholarship.

\section{References}

Armitage, P. \& Berry, G. (1987) Statistical Methods in Medical Research (2nd Edn). Blackwell Scientific Publications, Oxford.

Armstrong, D.T., Pfitzner, A.P., Warnes, G.M., Ralph, M.M. \& Seamark, R. F. (1983) Endocrine responses of goats after induction of superovulation with PMSG and FSH. Journal of Reproduction and Fertility 67, 395-401.

Bomsel-Helmreich, O., Huyen, L.Vu.N. \& DurandGasselin, I. (1989) Effects of varying doses of HCG on the evolution of preovulatory rabbit follicles and oocytes. Human Reproduction 6, 636-642.

Bonner, W.M. \& Laskey, R.A. (1974) A film detection method for tritium-labelled proteins and nucleic acids in polyacrylamide gels. European Journal of Biochemistry 46, 577-582.
Booth, W.D., Newcomb, R., Strange, H., Rowson, L.E.A. \& Sacher, H.B. (1975) Plasma oestrogen and progesterone in relation to superovulation and egg recovery in the cow. Veterinary Record 97, 366-369.

Callesen, H., Greve, T. \& Hyttel, P. (1986) Preovulatory endocrinology and oocyte maturation in superovulated cattle. Theriogenology 25, 71-86.

Crisman, R.O., McDonald, L.E. \& Thompson, F.N. (1980) Effects of progesterone or oestradiol on uterine tubal transport of ova in the cow. Theriogenology $13,141-153$.

Crosby, I.M., Osborn, J.C. \& Moor, R.M. (1981) Follicle cell regulation of protein synthesis and developmental competence in sheep oocytes. Journal of Reproduction and Fertility 62, 575-582. 
Evans, G. \& Armstrong, D.T. (1984) Reduction of sperm transport in ewes by superovulation treatments. Journal of Reproduction and Fertility 70, $47-53$.

Farmer, S.W. \& Papkoff, H. (1979) Immunochemical studies with pregnant mare serum gonadotrophin. Biology of Reproduction 21, 425-431.

Henderson, K.M., Weaver, A., Wards, R.L., Ball, K., Lun, S., Mullin, C. \& McNatty, K.P. (1990) Oocyte production and ovarian steroid concentrations of immature rats in response to some commercial gonadotrophin preparations. Reproduction Fertility and Development 6, 671-682.

Jensen, A.M., Greve, T., Madej, A. \& Edqvist, L.E. (1982) Endocrine profiles and embryo quality in the PMSG-PGF2 $\alpha$ treated cow. Theriogenology 18, 33-44.

Kubelka, M., Motlik, J., Fulka, J., Jr, Prochazka, R., Rimkevicova, Z. \& Fulka, J. (1988) Time sequence of germinal vesicle breakdown in pig oocytes after cycloheximide and $p$-aminobenzamidine block. Gamete Research 19, 423-431.

Kumar, J., Osborn, J.C., Cameron, A.W.N., Batt, P.A. \& Trounson, A.O. (1990) Premature condensation of chromatin induced in goat (Capra hircus) oocytes after gonadotrophin treatment. Reproduction Fertility and Development 6, 661-670.

Kumar, J., Osborn, J.C. \& Cameron, A.W.N. (1991) Luteinising Hormone and Follicle Stimulating Hormone induce premature condensation of chromatin in goat (Capra hircus) oocytes. Reproduction Fertility and Development 3, 585-591.

Laskey, R.A. \& Mills, A.D. (1975) Quantitative film detection of ${ }^{3} \mathrm{H}$ and ${ }^{14} \mathrm{C}$ in polyacrylamide gels by fluorography. European Journal of Biochemistry 56, 335-34l.

McGaughey, R.W. (1977) The culture of pig oocytes in minimal medium and the influence of progesterone and oestradiol-17 $\beta$ on meiotic maturation. Endocrinology 100, 39-45.

McIntosh, J.E., Moor, R.M. \& Allen, W.R. (1975) Pregnant mare serum gonadotrophin: rate of clearance from the circulation of sheep. Journal of Reproduction and Fertility 44, 95-100.

Moor, R.M. (1978) Role of steroids in the maturation of ovine oocytes. Annales de Biologie Animale Biochimie Biophysique 18, 477-482.

Moor, R.M. \& Crosby, I.M. (1986) Protein requirements for germinal vesicle breakdown in ovine oocytes. Journal of Embryology and Experimental Morphology 94, $207-220$.

Moor, R.M. \& Gandolfi, F. (1987) Molecular and cellular changes associated with maturation and early development of sheep eggs. Journal of Reproduction and Fertility Supplement 34, 55-69.

Moor, R.M. \& Trounson, A.O. (1977) Hormonal and follicular factors affecting maturation of sheep oocytes in vitro and their subsequent developmental competence. Journal of Reproduction and Fertility 49, 101-109.

Moor, R.M., Polge, C. \& Willadsen, S.M. (1980) Effect of follicular steroids on the maturation and fertilization of mammalian oocytes. Journal of Embryology and Experimental Morphology 56, 319-335.

Moor, R.M., Osborn, J.C., Cran, D.G. \& Walters, D.E. (1981) Selective effects of gonadotrophins on cell coupling, nuclear maturation and protein synthesis in mammalian oocytes. Journal of Embryology and Experimental Morphology 61, 347-365.

Moor, R.M., Osborn, J.C. \& Crosby, I.M. (1985) Gonadotrophin-induced abnormalities in sheep oocytes after superovulation. Journal of Reproduction and Fertility 74, 167-172.

O'Farrell, P.H. (1975) High resolution, two dimensional electrophoresis of proteins. Journal of Biological Chemistry 250, 4007-4021.

Osborn, J.C. \& Moor, R.M. (1983a) The role of steroid signals in the maturation of mammalian oocytes. Journal of Steroid Biochemistry 19, 133-137.

Osborn, J.C. \& Moor, R.M. (1983b) Time-dependent effects of $\alpha$-amanitin on nuclear maturation and protein synthesis in mammalian oocytes. Journal of Embryology and Experimental Morphology 73, 317-338.

Osborn, J.C., Moor, R.M. \& Crosby, I.M. (1986) Effect of alterations in follicular steroidogenesis on the nuclear and cytoplasmic maturation of ovine oocytes. Journal of Embryology and Experimental Morphology 98, 187-208.

Richards, J.S. (1980) Maturation of ovarian follicles: actions and interactions of pituitary and ovarian hormones on follicular cell differentiation. Physiology Reviews 60, 51-89.

Robinson, T.J. (1973) Factors involved in the failure of sperm transport and survival in the female reproductive tract. Journal of Reproduction and Fertility Supplement 18, 103-109.

Schams, D., Menzer, Ch., Schallemberger, F., Hoffman, B., Hahn, J. \& Hahn, R. (1978) Some studies on pregnant mares' serum gonadotrophin (PMSG) and on endocrine responses after application for superovulation in cattle. In Control of Reproduction in the Cow, pp. 122-143. Ed. J.M. Sreenan. Martinus Nijhoff, The Hague.

Soupart, P. (1974) The need for capacitation of human sperm: functional and ultrastructural observations. In Biology of the Spermatozoa, pp. 182-191. Eds E. S. E. Hafez \& C. Thibault. Karger, Basle.

Thibault, C. (1977) Are follicular maturation and oocyte maturation independent processes? Journal of Reproduction and Fertility 51, 1-15.

Trounson, A.O. \& Moore, N.W. (1974) Fertilization in the ewe following multiple ovulation and uterine insemination. Australian Journal of Biological Science 27, 301-304.

Received 18 March 1991 